\title{
Perceptions of Blended Learning Competencies and Obstacles among Educational Technology Students in Light of Different Anxiety Levels and Locus of Control
}

\author{
Osamah Ahmad Aldalalah \\ Jadara University, Jordan \\ Al-Mothana M. Gasaymeh \\ Al-Hussein Bin Talal University, Jordan
}

\begin{abstract}
The purpose of this study was to investigate the effects of locus of control and anxiety level on the Jordanian educational technology students' perceived blended learning competencies and obstacles. The independent variables were the locus of control (Internal, External) and anxiety level (Low, Moderate, High). The dependent variables were the students' perceptions of their personal blended leaning competences (Knowledge \& Technological) and students' perceptions of the obstacles of blended leaning. The study sample consisted of 107 undergraduate educational technology students. Inferential statistics were conducted to analyze the data. Analysis of variance and pairwise post hoc tests were carried out to examine the main effects as well as the interaction effects of the independent variables on the dependent variables. The findings of this study showed that students with internal locus of control performed significantly better than external locus of control students in blended learning competencies (Knowledge \&Technological) and blended learning obstacles. The findings of this study also showed that moderate anxiety students performed significantly better than low and high anxiety students in blended learning competencies (Knowledge \&Technology) and blended learning obstacles. Finally, the study found that there was no significant difference between the low and high anxiety students in blended learning obstacles.
\end{abstract}

Keywords: Blended learning competencies; Blended learning obstacles; Locus of control; Anxiety level

\section{Introduction}

Reform in higher education is a strategy that aims to make a major adjustment in educational methods and theories (Khader, 1993). The international educational systems have agreed on the important role of the lecturers in public development and the necessity for high quality education systems that focus on the preparation of the student in terms of mental aptitudes and abilities (Qtami, 2005). The great potentials of the human mind and how it may be developed demonstrate the importance of having open minded learners who meet the expectations of their communities and perform effectively in the global market. Preparing students in the third millennium necessitates a higher level of cognitive adaptability (Al-atom, 2004). In order to improve the higher education outcomes, the planning of curricula was sought to develop educational materials that are composed based on the findings of the 
academic research in psychology and the related cognitive psychology fields. The adoption of traditional educational systems based on memorization, reiteration, or lecturing would make students feel bored. The psychological interests and integrated personality of individuals become a major concern for higher education professionals. This fact is illustrated by the accelerating pace of modern life and diligent work for living which adds a burden characterized by psychological stressors. Self-understanding and control is necessary for the human to adapt to the surrounding environment. Insecure relationship with life starts out when one starts thinking introspectively towards inability to adapt (Albdoor, 2006). Therefore, when educators select a new mode of instruction (e.g., blended learning) there is need to understand the students' characteristics and their effects on the students' perceptions of such new mode of instruction.

\section{Blended Learning}

Higher education that is based on blended learning combines both the traditional and modern technology in education (Long, Vignare, Rappold, \& Mallory, 2007). Blended learning has various advantages including effort and time-saving as well as cost effectiveness. In, addition blended learning allows the possibility to improve students' achievement level, and helps teachers create an environment that is most attractive to learners (Badawi, 2009; Myllymäki, 2011). Despite perceived significance and seemingly viable preliminary outcomes, blended learning approach is still underutilized due to a variety of difficulties and challenges. Therefore, it is important, to provide meaningful future vision on how best to introduce blended learning in the teaching-learning process (Haydar, 2009). Vaughan (2007) emphasized on the benefits produced by blended learning for students, faculty members, and administrators. The results of Vaughan's (2007) study showed that blended learning allows flexible time schedules, improves learning outcomes, encourage learners take responsibility on their own learning, allow learners to use modern technology, creates opportunity for teacher-student interaction, increase student involvement in learning, change educational environment into one more elastic, and open for development and continuous improvement. Furthermore, blended learning creates new opportunity to improve reputation of higher education institutions (HEl's) and cut down operating costs (Al-Ghamdi, 2011).

Blended learning is referred to as a process by which teachers use the Internet and classroom methods to provide students with a set of skills (Kitchenham, 2005); and it defined as the learning that combines the characteristics of both traditional classroom teaching and online learning in an integrated model that makes best use of technologies available for both modes of learning (Akkoyunlu \& Soylu, 2008). However, Cameron (2005) viewed blended learning as a form of learning in which online learning is integrated with the traditional classroom learning within single framework, where online learning capabilities, whether computer-based or Internet-based, are employed such as computer lab and smart class, and where teacher and students meet online most of the time. On the other hand, Daood and Mahmood (2013) defined blended learning as educational method based on blending different means by which information is communicated consistently so as to achieve the educational outcomes. Furthermore, Osguthorpe and Graham (2003) argued that blended learning is based on the employment of technology and selection of the most appropriate instructional means by which to solve problems that are related to classroom management, and using learningoriented activities that require accuracy and mastery. Blended learning forms natural evolution of learning in the contemporary time and proposes splendid solutions to cope with current 
educational challenges and to meet educational needs of individuals since it is a formula of teaching, learning and training that integrated online learning with traditional classroom teaching within one framework (Thome, 2003). In addition, blended learning approaches allow using electronic capabilities whether computer-based or Internet-based, in lecturing and training sessions typically undertaken in virtual classrooms enabled with information technology and communication capabilities (Orhan, 2008; Shehab, 2007). The review of the previous definitions of blended learning clearly shows that blended learning combines key elements of both traditional learning such as teacher-student interaction in classroom with the key feature of online learning as represented by the use of modern technology like computer, Internet, chatting, and emails to improve the learning-teaching process. The authors (i.e. Abudlaati \& Alsayed, 2007; Al-Ghamdi, 2011) argued that when designing blended learning, the environment should carefully planned in order to achieve effective use of the online learning technology and to identify program medium functionality. Furthermore, Sethy (2008) stressed on the need to make sure that teachers and students own the skills to use online learning technology, as lacking such skills would compromise the learning; and to hold public session joining teachers and students together. In a blended learning program the goals, plan, implementation, and strategy should be clearly defined; teachers should be available in right time to respond to students' queries whether online or face-to-face interaction in classroom; and learning resources should be divers to meet individual differences among learners (Robison, 2004).

Gulbahar and Madran (2009) agreed with the literature that there are four major areas including numerous factors that should be taken into account when developing a blended learning environment, including technology, teachers, students, and pedagogy. As in traditional teaching, blended learning requires structuring content so that to be accessible to achieve effective learning by associating new knowledge with the previous one (Altun, Gulbahar, \& Madran, 2008; Zubi \& Bany, 2012). Kim, Bonk, and Teng (2009) indicated that blended learning is going to be widely used in teaching because there are increased awareness of the need of providing training for personnel on blended learning implementation considering its positive outcomes in education.

Blended learning can be divided into four levels or classes of varied complexity ranging from simple (least integration between traditional and online learning) to complex (most integration between traditional and online learning forming a new learning that has its unique qualities and inseparable components). There are numerous factors that need to be available for blended learning for successful implementation. Al-Jasem (2011) indicated that most importantly, effective student-teacher communication should be in place, in addition to forming teams to enable all participants to get involved, assign their roles, and to encourage self-learning. Al-Ghamedi (2010) argued that for blended learning to be effective, students should be involved in choosing communication means most appropriate for them taking in mind continuous and constant communication with all parties of the teaching-learning process. The content also should be presented in various forms and models, for example via the web or by using videocassette recordings (Stacey \& Gerbic, 2008).

As there are success factors, there are also hindrances that impede effective implementation of the blended learning approach. Al-Shyukh (2008) stressed on technological hindrances such as software programs, server speed, and abrupt technical troubles. In addition, there are the human hindrances of blended learning that are related to lack of skills and sufficient training qualifying students, teachers, and administrators to effectively manage the blended learning approach (Vaughan, 2007). On the other hand, Al-Shammari (2007) emphasized on hindrances 
related to curriculum in terms of being difficult to carry out from some aspects that require too much effort for preparation, and other hindrances related to assessment, control, and feedback. Finally, there are financial hindrances as represented by costly infrastructure required to carry out the blended learning approach.

The students represent one of the key components that need to be considered in the process of developing and utilizing blended learning. Students' psychological characteristics needed to be examined to assess their readiness for blended learning. The following two sections discussed two dimensions of students' psychological characteristics: Anxiety and locus of control.

\section{Anxiety}

The stress results from one being anxious about his/her life. Unwelcome life procedures result in stress and morbidity that affects one's self idea and life style. Unwelcome events need greater flexibility to new situations (Bishop, 2009). People would feel anxious as a result of day-to-day chores, responsibilities and increased stress of life (Duck, 1992). Anxiety is one of the learner's most significant individuality, and is one of the most studied variables in the context of the learning and teaching process. Alshawa and Alhayek (2009) conceptualized anxiety as an emotional state besieged with unordinary feelings. There are different kinds of anxiety such as test anxiety, speech anxiety, and mathematics anxiety. These types of anxiety describe unwanted emotional feeling like fear and a pervasive feeling that something terrible is about to happen and that, when it does, the one won't be able to cope with it (Warr \& Downing, 2000). When students' anxiety reaches a high level, the performance will be weak in the average learning contexts. Otherwise, students who report low levels of anxiety would have better performance (Birenbaum, 2007).

Batayneh, Aljrah, and Ghawanima (2007) defined anxiety as a painful psychological state resulting from the individuals' feelings of helplessness in conflict and challenging situations. Anxiety is an unpleasant ambiguous emotion that has a variety of negative psychological and physical symptoms. Hawwash and Elemat (2006) defined anxiety as a state of discomfort and future events related concerns. It involves feelings of distress, preoccupation, and anticipation of bad events. Oluko, Ozuredi, and Sakaci (2009) proposed two dimensions of anxiety: the state of anxiety and the trait of anxiety.

The state of anxiety is an unpleasant emotional response characterized by subjective feelings involving distress, fear, and irritability. It is characterized by provoking the neural system and increasing attention (Poborski, Yurina, Lopatskaya, \& Deryagina, 2009). The state of anxiety occurs when the person has subjective perception that a certain stimulus or a specific situation will be threatening to him or her, the state of anxiety changes across time, it is temporary, and it easily disappears (Hong \& Karstensson, 2002). The trait of anxiety is characterized by relative stability and its levels do not vary within the same individual but varies across individuals according to previous knowledge and the past experiences (Oluko, Ozuredi, \& Sakaci, 2009). Alahmad (2001) distinguishes between the trait of anxiety and the state of anxiety on the basis that the levels of the state of anxiety changes across situations but the trait of anxiety changes across individuals.

Students who have high anxiety have often been distinguished by low achievement (Effandi \& Nordin, 2008). This means that anxiety in the different states prevents recall of previously 
learned knowledge. This fact has been explained by stating that they split their attention between the needs of the learning task and other learning task related to aspects consisting mainly of negative self-ability and demonstrating feelings of weakness (Fong \& Aldalalah, 2010). As for students who have lower levels of anxiety, they focused all their attention on the learning task; this demonstrates good performance (Sarason, 1972).

Anxiety is one of the learner's most important characteristics, and is one of the most studied variables in the context of the learning and teaching process (Fong \& Aldalalah, 2010). Anxiety plays an important role on uneasiness, concern, worry, fear, and resistance to using technology in educational purposes (Sa'ari, Luan, \& Roslan, 2005). Researchers within the field of education started to focus on technology anxiety because the use of technology in the classroom has grown (Zayadan, 2010). Not all teachers and students are comfortable using technologies in the process of teaching and learning. Technology anxiety is a generalized emotion of uneasiness, apprehension, anxiousness of coping, or distress in anticipation of negative outcomes from computer-related operations (Chang, 2005). Technology/computer anxiety is one possible barrier to the acquisition of computer skills and has thus been associated with students' poor performance on tasks involving simple computer operations (Mahar, Henderson, \& Deane 1997).

\section{Locus of Control}

Locus of control has an essential role in the responses of individuals towards the different responses that exist in the surrounding environment (Shabazz, 2007). Halpert and Hill (2011) proposed a person's locus of control is where that person places the main causation of events in their life. Rotter (1966) suggested that different individuals have different perspectives for the motivation surrounding them; thus, their responses vary as a result of these individual perceptions. Some individuals perceive the reinforcement source as internal, while others see it as external. People ascribe many reasons for their success or failure in performing a certain task, resulting in having different motivations for performing different tasks (Anderson, Hattie, \& Hamilton, 2005). Some people may attribute the consequences of their performance, whether these consequences were positive or negative, to their personal efforts. Others may attribute the consequences of their performance to luck (Jay, 2007). Rotter (1990) argues that people acquire their general expectations about their personal performance through their past experiences with different kinds of reinforcements or through their expectations to get a specific reinforcement as a result of performing a certain task. Consequently, one may say that there are two kinds of individuals based on their reinforcement related to personal expectations: people with internal locus of control and people with external locus of control. Locus of control plays one of the universal and influencing reasons on human behavior and achievement (Anu \& Shannan, 2011; Nunn \& Nunn, 1993; Rotter, 1992). Stocks, April, and Lynton (2012) proposed that people with internal locus of control expect to acquire reinforcement through their individual efforts and their performance. Otherwise, people with external locus of control expect to acquire their reinforcement through luck or fate (Halpert \& Hill, 2011).

Internal or external locus of control plays an important role for students to sustain the efficacy and usefulness of learning performance (Konan, 2011). Many studies have been done using locus of control in several topics such as management, education, achievement, motivation, attitudes, responsibility, satisfaction, parenting, health, and weight loss (Levy, 2007). There are studies that focused on the interaction between technology and locus of control. For instance, 
Barnard, Lan, To, Paton, and Lai (2009) study found that the e-learning environment was the most beneficial for the students with an internal locus of control who believed they had control over events and situations in their lives. Bowen (1996) concluded that students with internal accountability beliefs generally perform better than students with an external locus of control in online courses. In Cascio, Botta, and Anzaldi (2013) study, the researchers found that online learning degree is influenced by the combined effect of internal locus of control.

\section{Purpose of the study}

The present study intended to investigate the effects of educational technology students' locus of control and anxiety levels on their blended learning competencies and their perceived obstacles of blended learning.

Four research questions guided the study:

1. What is the effect of students' locus of control on their perceptions of personal blended leaning competences (knowledge and technological)?

2. What is the effect of students' locus of control on their perceived obstacles of blended leaning?

3. What is the effect of students' levels of trait anxiety on their perceptions of personal blended learning competences (knowledge and technological)?

4. What is the effect of students' levels of trait anxiety on their perceived obstacles of blended leaning?

\section{Methods}

Cross-sectional survey design was selected to investigate the Jordanian educational technology students' perceptions of their blended learning competencies and their perceived obstacles of blended learning in their education. In addition, the survey contained two scales that aimed to assess students' levels of anxiety and of locus of control. Quantitative data were collected using a questionnaire type instrument.

\section{Sample}

The sample of this study comprised all educational technology students $(n=107)$ enrolled in Jadara University in the second semester for the 2012/2013 academic year. The sample of this study consisted of 46 male and 61 female students. All the respondents were between the ages of 19 to 22 years old. All students were from Jordan, where they all had a homogenous mother tongue (Arabic), exposure to English as a foreign language, educational system, and cultural background.

\section{Study Setting}

The study took place in the Department of Educational Technology, College of Education, Jadara University in Jordan. The participants enrolled in a bachelor's program in educational 
technology. The goal of the program is to provide students with the required knowledge and skills in relation to theory and practice of integrating information and communication technologies in teaching and learning. The questionnaire was in paper-and-pencil format. The questionnaire was administrated and collected in-classes with the help of research assistants. The participations in the study were completely voluntary. The participants were asked to respond to the questionnaire anonymously. No extra credits were given for completing the questionnaire or taking part in the study.

\section{Instruments}

The basic instrument used in this study was a questionnaire. The questionnaire consisted of five sections. The first section aimed to collect demographic data about the students such as gender and age. The other sections consisted of four Likert-type scales, where each item in these scales was followed by a set of five possible answers: Strongly Agree, Agree, Neither, Disagree, and Strongly Disagree. The following sections summarize the descriptions of the four scales.

Blended Learning Scale: Based on the literature review conducted on the blended learning in teaching, the Blended Learning Scale was developed by the researchers to identify students' views regarding blended learning environment. The scale was reviewed and confirmed by experts in the fields of educational technology, curriculum development, measurement and evaluation. The scale consisted from 39 items. This is in line with the opinions of experts who have taken into consideration the suitability for the students (the study sample). Statements in the scale were categorized in two sub-scales; the first sub-scale consisted from 13 items that were prepared to identify students' perceptions of their blended learning knowledge competencies and the second sub-scale consisted from 26 items that were prepared to identify students' perceptions of their blended learning technological competencies. The reliability coefficient of Blended Learning Scale was computed by the implementation of Cronbach's Alpha, where it was 0.81 for the whole scale. The internal consistency coefficient for this instrument was 0.84 .

Obstacles of Blended Learning Scale: In order to achieve the objectives of the present study, it was essential to involve a variety of research instruments. The Obstacles of Blended Learning Scale, which was administered on the students in this study, was developed by the researchers based on the previous literature review about blended learning. The Obstacles of Blended Learning Scale consisted of 15 items that were prepared to identify students' perceived obstacles of blended learning. The reliability coefficient of Obstacles of Blended Learning Scale was computed by the implementation of Cronbach's Alpha, where it was 0.79 for the whole scale. The internal consistency for this scale (Arabic version) was 0.83 .

Trait Anxiety Scale: The Trait Anxiety Scale is adopted from Asiri (2007). This scale is used to measure the trait anxiety levels of students. The scale consists of 51 items. The reliability coefficient for this scale was computed by the implementation of Cronbach's Alpha, where it was found to be 0.86 for the whole scale. The internal consistency for this instrument was 0.92 .

Trait anxiety of the students was divided into three levels: Low, Moderate, and High. The levels are identified based on the following equation: 


$$
\begin{gathered}
\mathrm{L}=\text { Low } \mathrm{M}=\text { Moderate } \quad \mathrm{H}=\text { High } \\
\mathrm{H}(\text { range })=[3.50-5.00] \\
\mathrm{M}(\text { range })=[2.50-3.49] \\
\mathrm{L} \text { (range })=[0-2.49] .
\end{gathered}
$$

Locus of Control Scale: This scale, the Intellectual Achievement Responsibility, is a measure of the locus of control for students. This instrument was prepared by Bani Khalid (2009). The scale consisted of 29 items yielding the description of internal locus of control versus external locus of control factors. The number of items that refer to external locus of control was 12 items and the number of items that refers to internal locus of control was 11 items; 6 items were neglected because they are used to disguise. Each item describes intellectual success or failure situation. The total score of the Locus of Control Scale is 23. Students received a score of " 0 " for an internal answer and a score of " 1 " for an external answer or for the case of no answer on each item. The locus of control for students was divided into two levels: Internal (0 8) and External (9-23). The reliability coefficient for this instrument was computed by the implementation of Cronbach's Alpha, where it was 0.84 for the whole scale. The internal consistency for this instrument was 0.86 .

Face validity of the questionnaire instrument was judged by a panel of experts in the field of educational technology. Content validity of the questionnaire in this research was also justified by the panel of experts. The feedback and comments received from the panel of experts were employed to establish the necessary clarifications, changes, and modifications before and after piloting the study.

\section{Data Analysis}

Inferential statistical techniques were conducted to analyze the data. Analysis of variance (ANOVA) was used to examine the effect of students' locus of control on their perceptions of personal blended learning competencies (knowledge and technology) as well as their perceived obstacles of blended learning. ANOVA and post hoc tests were carried out to examine the effects of students' levels of trait anxiety on their perceptions of personal blended learning competencies (knowledge and technology) as well as their perceived obstacles of blended learning.

\section{Results}

This study provided empirical data for the Jordanian educational technology students' perceptions of their blended learning competencies and their perceived obstacles of blended learning in Jadara University. Furthermore, the present study examined the relationship between the two dependent variables (students' perceptions of their blended learning competencies (knowledge \& technology)) and their perceived obstacles of blended learning in Jadara University and two independent variables (students' locus of control and students' levels of trait anxiety). 


\section{The Effect of Locus of Control on Blended Leaning Competences}

In order to answer the first research question that aimed to examine the effect of students' locus of control on their perceptions of personal blended leaning competences (knowledge and technology), the means of students' scores in the Technological competencies scale were compared based on their locus control. In addition, the means of students' scores in the Knowledge competencies scale were compared based on their locus control.

The results showed that technological competencies score mean $(M=89.65)$ for the internal locus of control group was higher than the technological competencies mean score $(M=75.50)$ for the external locus of control group. The knowledge competencies mean score $(M=50.93)$ for the internal locus of control group was higher than the Knowledge competencies mean score $(M=44.12)$ for the external locus of control group.

The total competencies mean score $(M=140.58)$ for the internal locus of control group is higher than the knowledge competencies mean score $(M=119.62)$ for the external locus of control group. Table 1 shows technological competencies and knowledge competencies mean scores with different locus of control (Internal \& External)

Table 1. Technological Competencies and Knowledge Competencies Mean Scores with Different Locus of Control (Internal \& External)

\begin{tabular}{llllr}
\hline Groups & Locus of control & Mean & Std. Deviation & $\mathrm{N}$ \\
\hline Technological & Internal & 89.6512 & 34.28514 & 43 \\
& External & 75.5000 & 33.90650 & 64 \\
& Total & 81.1869 & 34.60672 & 107 \\
\hline Knowledge & Internal & 50.9302 & 15.81951 & 43 \\
& External & 44.1250 & 11.57652 & 64 \\
& Total & 46.8598 & 13.78572 & 107 \\
Total & Internal & 140.5814 & 45.25127 & 43 \\
& External & 119.6250 & 41.44742 & 64 \\
& Total & 128.0457 & 44.03309 & 107 \\
\hline
\end{tabular}

In order to reduce the statistical error and examine if there were significant differences in students' responses to the blended learning competencies scale based on their locus of control, a comparison of the means of students' responses to blended learning competencies scale was made among the two groups, students with internal locus of control and students with external locus of control using the ANOVA procedure (Table 2).

The values $[F(1,105)=4.440$; Mean Square $=5150.49$; and $p=.037]$ show a significant difference between the technological competencies mean scores of students with different locus of control (Internal \& External). The values $[F(1,105)=6.598$; Mean Square $=1191.10$; and $p=.012]$ show a significant difference between the knowledge competencies mean scores of students with different levels of locus of control (Internal \& External). The values $[F(1,105)=6.106$; Mean 
Square=11295.30; and $p=.015$ ] show a significant difference between the total competencies score of students with different levels of locus of control (Internal \& External

Table 2. ANOVA of the Technological Competencies and Knowledge Competencies Mean Scores with Different Levels of Locus of Control (Internal \& External)

\begin{tabular}{|c|c|c|c|c|c|c|}
\hline & & Sum of Squares & $\mathrm{df}$ & $\begin{array}{l}\text { Mean } \\
\text { Square }\end{array}$ & $\mathrm{F}$ & Sig. \\
\hline \multirow[t]{3}{*}{ Technological } & $\begin{array}{l}\text { Between } \\
\text { Groups }\end{array}$ & 5150.494 & 1 & 5150.494 & 4.440 & .037 \\
\hline & Within Groups & 121797.767 & 105 & 1159.979 & & \\
\hline & Total & 126948.262 & 106 & & & \\
\hline \multirow[t]{3}{*}{ knowledge } & $\begin{array}{l}\text { Between } \\
\text { Groups }\end{array}$ & 1191.106 & 1 & 1191.106 & 6.598 & .012 \\
\hline & Within Groups & 18953.791 & 105 & 180.512 & & \\
\hline & Total & 20144.897 & 106 & & & \\
\hline \multirow[t]{3}{*}{ Total } & $\begin{array}{l}\text { Between } \\
\text { Groups }\end{array}$ & 11295.301 & 1 & 11295.301 & 6.106 & .015 \\
\hline & Within Groups & 194229.465 & 105 & 1849.804 & & \\
\hline & Total & 205524.766 & 106 & & & \\
\hline
\end{tabular}

\section{The Effect of Locus of Control on Blended Leaning Obstacles}

In order to answer the second research question that aimed to examine the effect of students' locus of control on their perceived obstacles of blended leaning, the means of students' scores in the obstacles of blended leaning scale were compared based on their locus control. The results showed obstacles mean score $(M=43.68)$ for the external internal locus of control group is higher than the obstacles mean score $(M=36.11)$ for the internal locus of control group. Table 3 shows mean scores of obstacles scale with different locus of control (Internal \& External)

Table 3. Blended Learning Perceived Obstacles Mean Scores with Different Locus of Control (Internal \& External)

\begin{tabular}{lllll}
\hline Groups & Locus of control & Mean & Std. Deviation & $\mathrm{N}$ \\
Obstacles & Internal & 36.1163 & 13.71167 & 43 \\
& External & 43.6875 & 14.25936 & 64 \\
& Total & 40.6449 & 14.46548 & 107 \\
\hline
\end{tabular}

In order to reduce the statistical error and examine if there were significant differences in students' responses to the blended learning perceived obstacles scale based on their locus of control, a comparison of the means of students' responses to blended learning perceived obstacles scale was made among the two groups, students with internal locus of control and students with external locus of control using the ANOVA procedure (Table 4). 
Table 4. ANOVA of the Blended Learning Perceived Obstacles Mean Scores with Different Locus of Control (Internal \& External)

\begin{tabular}{lllllll}
\hline & & Sum of Squares & df & $\begin{array}{l}\text { Mean } \\
\text { Square }\end{array}$ & F & Sig. \\
\hline Obstacles & Between & 1474.336 & 1 & 1474.336 & 7.476 & .007 \\
& Groups & 20706.169 & 105 & 197.202 & & \\
& Within Groups & 22180.505 & 106 & & & \\
\hline
\end{tabular}

The results showed that the values $[F(1,105)=7.476$; Mean Square $=1474.33$; and $p=.007]$ show a significant difference between the perceived obstacles mean scores of students with different levels of locus of control (Internal \& External).

\section{The Effect of Anxiety on Blended Leaning Competences}

In order to answer the third research question that aimed to examine the effect of students' level of anxiety on their perceptions of personal blended leaning competences (knowledge and technology), the means of students' scores in the Technological competencies scale were compared based on their levels of anxiety. In addition, the means of students' scores in the Knowledge competencies scale were compared based on their level of anxiety.

The results showed that the technological competencies mean score $(M=103.15)$ for moderate anxiety group was higher than the technological competencies mean score $(M=77.40)$ for the low anxiety group. The mean of technological competencies score $(M=77.40)$ for the low anxiety group was higher than the mean of the technological competencies score $(M=57.16)$ for the high anxiety group.

The knowledge competencies mean score $(M=53.86)$ for moderate anxiety group was higher than the knowledge competencies mean score $(M=46.96)$ for the low anxiety group. The mean of knowledge competencies score $(M=46.96)$ for the low anxiety group was higher than the mean of the knowledge competencies score $(M=38.22)$ for the high anxiety group.

The total competencies mean score $(M=157.02)$ for moderate anxiety group was higher than the total competencies mean score $(M=124.37)$ for the low anxiety group. The mean of total competencies score $(M=124.37)$ for the low anxiety group was higher than the mean of the total competencies score $(\mathrm{M}=95.38)$ for the high anxiety group.

Table 5 shows knowledge competencies, Technological competencies mean scores with Different levels of Anxiety (Low, Medium, High) 
Table 5. Technological Competencies and Knowledge Competencies Mean Scores with Different Levels of Anxiety (Low, Medium, High)

\begin{tabular}{llllr}
\hline Groups & Anxiety & Mean & Std. Deviation & N \\
\hline Technological & Low & 77.4074 & 31.69113 & 27 \\
& Moderate & 103.1591 & 26.54697 & 44 \\
& High & 57.1667 & 28.35137 & 36 \\
& Total & 81.1869 & 34.60672 & 107 \\
\hline Knowledge & Low & 46.9630 & 13.13680 & 27 \\
& Moderate & 53.8636 & 12.39766 & 44 \\
& High & 38.2222 & 10.95996 & 36 \\
\hline Total & Total & 46.8598 & 13.78572 & 107 \\
& Low & 124.3704 & 41.73188 & 27 \\
& Moderate & 157.0227 & 33.15256 & 44 \\
& High & 95.3889 & 32.63677 & 36 \\
& Total & 128.0467 & 44.03309 & 107 \\
\hline
\end{tabular}

In order to reduce the statistical error and examine if there were significant differences in students' responses to the blended learning competencies scale based on their levels of anxiety, a comparison of the means of students' responses to blended learning competencies scale was made among the groups, students with different levels of anxiety (Low, medium, high) using the ANOVA procedure (Table 6).

Table 6. ANOVA of the Technological Competencies and Knowledge Competencies mean Scores with Different Levels of Anxiety (Low, Medium, High)

\begin{tabular}{lllllll}
\hline & & Sum of & & Mean \\
& & Squares & df & Square & F & Sig. \\
\hline Technological & Between Groups & 42398.857 & 2 & 21199.428 & 26.076 & .000 \\
& Within Groups & 84549.405 & 104 & 812.975 & & \\
& Total & 126948.26 & 106 & & & \\
\hline knowledge & Between Groups & 4844.530 & 2 & 2422.265 & 16.465 & .000 \\
& Within Groups & 15300.367 & 104 & 147.119 & & \\
& Total & 20144.897 & 106 & & & \\
\hline Total & Between Groups & 75702.937 & 2 & 37851.469 & 30.323 & .000 \\
& Within Groups & 129821.82 & 104 & 1248.287 & & \\
& & 9 & & & & \\
& Total & 205524.76 & 106 & & & \\
& 6 & & & & \\
\end{tabular}

The values $[F(2.104)=26.07$; Mean Square $=21199.42 ; p=.000]$ show a significant difference between the technological competencies score of students with different levels of anxiety ( $L$, $M, H)$. The values $[F(2.104)=16.46$; Mean Square $=2422.26 ; p=.000]$ show a significant 
difference between the knowledge competencies score of students with different levels of anxiety $(L, M, H)$. The values $[F(2.104)=30.32$; Mean Square $=37851.46 ; p=.000]$ show a significant difference between the total competencies score of students with different levels of anxiety $(L, M, H)$. The ANOVA results of comparing student's anxiety across the three groups ( $L$, $\mathrm{M}, \mathrm{H}$ ) on the dependent variable (students' perceptions of their blended leaning competences) indicated that there were statistically significant differences between students' anxiety and perceptions of their blended leaning competences. Therefore, the researchers further investigated the univariate statistics results (ANOVA) by performing a post hoc pairwise comparison using the LSD command for dependent variable in order to identify where the differences in the means resided. Table 7 shows a summary of the post hoc comparisons among student responses for Technological Competencies and Knowledge Competencies across the three anxiety groups ( $L, M, H)$.

Table 7. Summary of Post Hoc Pairwise Comparisons

\begin{tabular}{|c|c|c|c|c|c|}
\hline $\begin{array}{l}\text { Dependent } \\
\text { Variable }\end{array}$ & (I) Anxiety & $\begin{array}{l}\text { (J) } \\
\text { Anxiety }\end{array}$ & $\begin{array}{l}\text { Mean Difference } \\
(I-J)\end{array}$ & Std. Error & Sig. \\
\hline & & & Lower Bound & $\begin{array}{l}\text { Upper } \\
\text { Bound }\end{array}$ & $\begin{array}{l}\text { Lower } \\
\text { Bound }\end{array}$ \\
\hline \multirow[t]{6}{*}{ Technological } & Low & Moderate & $-25.75168\left(^{*}\right)$ & 6.97043 & .000 \\
\hline & & High & $20.24074(*)$ & 7.25898 & .006 \\
\hline & Moderate & Low & $25.75168\left(^{*}\right)$ & 6.97043 & .000 \\
\hline & & High & $45.99242(*)$ & 6.40776 & .000 \\
\hline & High & Low & $-20.24074\left(^{*}\right)$ & 7.25898 & .006 \\
\hline & & Moderate & $-45.99242\left(^{*}\right)$ & 6.40776 & .000 \\
\hline \multirow[t]{6}{*}{ knowledge } & Low & Moderate & $-6.90067(*)$ & 2.96521 & .022 \\
\hline & & High & $8.74074(*)$ & 3.08796 & .006 \\
\hline & Moderate & Low & $6.90067(*)$ & 2.96521 & .022 \\
\hline & & High & $15.64141\left(^{*}\right)$ & 2.72585 & .000 \\
\hline & High & Low & $-8.74074(*)$ & 3.08796 & .006 \\
\hline & & Moderate & $-15.64141\left(^{*}\right)$ & 2.72585 & .000 \\
\hline \multirow[t]{6}{*}{ Total } & Low & Moderate & $-32.65236(*)$ & 8.63730 & .000 \\
\hline & & High & $28.98148\left(^{*}\right)$ & 8.99486 & .002 \\
\hline & Moderate & Low & $32.65236\left(^{*}\right)$ & 8.63730 & .000 \\
\hline & & High & $61.63384(*)$ & 7.94007 & .000 \\
\hline & High & Low & $-28.98148\left({ }^{*}\right)$ & 8.99486 & .002 \\
\hline & & Moderate & $-61.63384(*)$ & 7.94007 & .000 \\
\hline
\end{tabular}

There were significant differences between means of technological competencies in the moderate anxiety group and technological competencies in the low anxiety group $(M=103.1591, M=77.4074, p=0.000)$. There were significant differences between technological competencies in the moderate anxiety group and technological competencies in the high anxiety group ( $M=103.1591, M=57.1667, p=.000)$. Finally, there were significant differences 
between technological competencies in the low and high anxiety groups ( $M=77.4074$, $M=57.1667, p=.006)$. There were significant differences between knowledge competencies in the moderate anxiety group and knowledge competencies in the low anxiety group $(M=53.8636, M=46.9630, p=.022)$. There were significant differences between knowledge competencies in the moderate anxiety group and knowledge competencies in the high anxiety group ( $M=53.8636, M=38.2222, p=.000$ ). Finally, there were significant differences between knowledge competencies in the low and high anxiety groups ( $M=46.9630, M=38.2222, p=.006)$. There were significant differences between total competencies in the moderate anxiety group and total competencies in the low anxiety group ( $M=157.0227, M=124.3704, p=0.022)$. There were significant differences between total competencies in the moderate anxiety group and total competencies in the high anxiety group ( $M=157.0227, M=95.388, p=.000)$. Finally, there were significant differences between total competencies in the low and high anxiety groups $(\mathrm{M}=124.3704, \mathrm{M}=95.388, \mathrm{p}=.002)$.

\section{The Effect of Anxiety on Blended Learning Obstacles}

In order to answer the fourth research question that aimed to examine the effect of students' level of anxiety on their perceived obstacles of blended leaning, the means of students' scores in the obstacles of blended learning scale were compared based on their levels of anxiety. The results showed that the obstacles mean score $(M=45.16)$ for higher anxiety group was higher than the obstacles mean score $(M=44.85)$ for the low anxiety group. The mean of the obstacles score $(M=44.85)$ for the low anxiety group was higher than the mean of the obstacles score $(M=95.38)$ for the moderate anxiety group. Table 8 demonstrates obstacles mean scores with different levels of anxiety (Low, Medium, High)

Table 8. Obstacles Mean Scores with Different Levels of Anxiety (Low, Medium, High)

\begin{tabular}{llllr}
\hline Groups & Anxiety & Mean & Std. Deviation & N \\
\hline Obstacles & Low & 44.8519 & 15.31893 & 27 \\
& Moderate & 34.0000 & 13.07225 & 44 \\
& High & 45.6111 & 12.44709 & 36 \\
& Total & 40.6449 & 14.46548 & 107 \\
\hline
\end{tabular}

In order to reduce the statistical error and examine if there were significant differences in students' responses to the blended learning obstacles scale based on their levels of anxiety (Low, Medium, High), a one-way ANOVA test was conducted (Table 9).

Table 9. ANOVA of the Obstacles Mean Scores with Different Levels of Anxiety (Low, Medium, High)

\begin{tabular}{lllllll}
\hline & & Sum of & & Mean & & \\
& & Squares & df & Square & F & Sig. \\
\hline Obstacles & Between Groups & 3308.542 & 2 & 1654.271 & 9.116 & .000 \\
& Within Groups & 18871.963 & 104 & 181.461 & & \\
& Total & 22180.505 & 106 & & & \\
\hline
\end{tabular}


The values $[F(2.104)=9.11$; Mean Square $=16.5427 ; p=.000]$ show a significant difference between the obstacles score of students with different levels of anxiety $(L, M, H)$. Post hoc pairwise comparison using the LSD command for dependent variable was performed in order to identify where the differences in the means resided. Table 10 shows a summary of the post hoc pairwise comparisons among students responses for obstacles across the three anxiety groups $(L, M, H)$.

Table10. Summary of Post Hoc Pairwise Comparisons

\begin{tabular}{|c|c|c|c|c|c|}
\hline $\begin{array}{l}\text { Dependent } \\
\text { Variable }\end{array}$ & (I) Anxiety & $\begin{array}{l}\text { (J) } \\
\text { Anxiety }\end{array}$ & $\begin{array}{l}\text { Mean Difference } \\
(I-J)\end{array}$ & Std. Error & Sig. \\
\hline & & & Lower Bound & $\begin{array}{l}\text { Upper } \\
\text { Bound }\end{array}$ & $\begin{array}{l}\text { Lower } \\
\text { Bound }\end{array}$ \\
\hline \multirow[t]{6}{*}{ Obstacles } & Low & Moderate & $10.85185\left(^{*}\right)$ & 3.29316 & .001 \\
\hline & & High & -.75926 & 3.42949 & .825 \\
\hline & Moderate & Low & $-10.85185\left(^{*}\right)$ & 3.29316 & .001 \\
\hline & & High & $-11.61111\left(^{*}\right)$ & 3.02733 & .000 \\
\hline & High & Low & .75926 & 3.42949 & .825 \\
\hline & & Moderate & $11.61111\left(^{*}\right)$ & 3.02733 & .000 \\
\hline
\end{tabular}

Post hoc pairwise comparisons showed that there were significant differences between obstacles in the moderate anxiety group and obstacles in the low anxiety group ( $M=34.0000$, $M=44.8519, p=.001)$. There were significant differences between obstacles in the moderate anxiety group and obstacles in the high anxiety group ( $M=34.0000, M=45.6111, p=.000)$. Finally, there were no significant differences between obstacles in the low and high anxiety groups ( $M=44.8519, M=45.6111, p=.825)$.

\section{Discussion}

\section{Locus of Control and Blended learning}

This study found that there were significant differences in the competencies scores of students with internal and external locus of control. The results of this study highlight that the driving power behind the decision to get involved in blended learning is not seated in the students only. There are other possible academic explanations for this relationship, like motivation. If there is a reason for the student to participate in blended learning, the student will become interactive in the learning process. The result showed that students with an external locus of control are reluctant to adopt blended learning and they may prefer face-to-face teaching. Students in Jadara University with an internal locus of control value the use of blended learning more. However, students' appreciation of blended learning does not necessarily seem to be a reason for them to adopt blended learning. More importantly, students with an external locus of control may need extra help in the use of blended learning by instructors, because it is likely that they do not know what to do. Therefore, the students should be provided with educational and technological support during in blended learning.

Generally, internal locus of control students achieved higher competencies scores compared to external locus of control students. This finding of the present study is consistent with several 
studies (Anis, Mesci, \& Ovdur, 2011; Bowen,1996; Cascio, Botta, \& Anzaldi, 2013; Levy,2007; Lan, To, Paton, \& Lai, 2009).

There are several possible reasons for these results. According to Jay (2007), internal locus of control students will achieve higher competencies scores due to their persistent involvement in learning. The internal locus of control students assume personal responsibility on their actions as they are conscious to their ability to control many factors related to their academic achievement and general performance. Therefore, students with internal locus of control believe they can take control of and change events by their actions, so they view their ability and efficiency as the major determinant of the results of a task. On the other hand, external locus of control students disregard such factors relating to ability, effort, and skills in creating success and avoiding failure. They most often would attribute either failure or success to others. External locus of control students believe that the essential determinant of their achievement results is luck and destiny, and because of such uncontrollable factors, they consider their futile to exert any effort to achieve such tasks; thereby they would have negative expectations of performance results in any future task.

\section{Anxiety and Blended learning}

The results of this study indicated that there were significant differences in competencies regarding the three anxiety levels (Low, Moderate, High). The results can be attributed to the nature of blended learning and to the interactivity allowed in the blended learning. Blended learning stimulated the students' attention, provided new ways of delivering the lesson, and used new stimuli and strategies based on multimedia. In light of the students need, the blended learning in the current study provided learners with rich, vigorous, and exciting experiences that contributed to their positive attitudes, and because the blended learning is somewhat modern teaching methods, they motivated and enhanced the student's interests in specific fields. Taking into account the powerful role of technology in contemporary life, the importance of information technology advancements also boosted their positive attitudes towards blended learning.

The finding showed that anxiety is one of the factors that affect students' perceived competencies of blended learning use in the area of education. This study found that there were differences in the students' perceived competencies and obstacles among students with different levels of anxiety in the blended learning. Students with moderate level of anxiety may have ability in using blended learning. On the other hand, students with higher anxiety level were less likely to use blended learning in education. This indicates that a certain degree of anxiety (not too high and not to low) helps students in their learning and their attitudes towards modern teaching methods based on communication and information technology.

This finding is consistent with the results of several studies (Chang, 2005; Fong \& Aldalalah, 2010; Sa'ari, Luan, \& Roslan, 2005; Zayadan, 2010). The results of these studies showed that anxiety played a very important role in making users interested in the use of the technologies in educational settings.

There are some possible reasons for the results of this study. Minimal stimulus causes boredom among the low anxiety students whereas excessive stimulus will lower perceived 
competencies among the high anxiety students. This finding may explain the low perceived competencies observed among the low and the high anxiety students.

The low anxiety students may not pay sufficient attention to instruction whereas high anxiety students may feel that instruction may be too demanding. Anxiety plays an important role on uneasiness, concern, worry, fear, and resistance of using blended learning in educational purposes. The high anxiety students experience a high level of anxiety regardless of the technology difficulty and this may contribute to their low or unsatisfactory competencies.

There are many possible theoretical explanations for this relationship. The student's lack of competency in the use of technology could be contributing to the increased mental effort. As described earlier, the results from this study showed a strong negative correlation between blended learning perceived competencies and anxiety. Students with high levels of anxiety performed more poorly on the competencies. Fearfulness of using blended learning, make the students committing errors and mistakes when they use blended learning, sense they consider blended learning as a new thing in the field of education, and the lack blended learning skills, and confidence in handling blended learning applications. In order to increase the use of blended learning approaches by students who have a high anxiety level, they should be provided with the necessary training during the study period.

\section{References}

Abudlaati, H. \& Alsayed, A. (2007, September). The impact of the use of both e-learning and blended learning in design and production skills of educational Web sites among professional diploma students and their attitudes towards e-learning technology. The Third International Learning and Teaching Technology Conference. Egypt.

Akkoyunlu, B. \& Soylu, M. Y. (2008). A study of student's perceptions in a blended learning environment based on different learning styles. Educational Technology \& Society, 11(1), 183-193.

Alahmad, A. (2001). State and trait of anxiety and relationship with gender and specialization. Damascus University Journal, 1(17), 140-147.

Al-atom, A. (2004). Cognitive psychology. Amman: Dar Almaserh.

Albdoor, N. (2006). The level of psychological stress and its relationship to motivation level of the principles of the general secretariat for the Christian educational foundations in Jordan (Unpublished doctoral dissertation). Amman Arab University for Graduate Studies, Jordan.

Al-Ghamdi, F. (2011). The Effect of applying Blended Learning using Learning Management System (Blackboard) on the Achievement of the students of "The Production and Use of Instructional Media Course" in King Saud University. Master Thesis (Unpublished), King Saud University.

Al-Ghamedi, Khadija. (2010). Blended learning effectiveness acquisition unit skills program presentations (PowerPoint) to secondary second grade students in Riyadh. (Unpublished master's thesis). King Saud University, Saudi Arabia.

Al-Jasem, O. (2011). The status of the application of blended learning Experiences in Damascus schools and obstacles of using it and students attitudes towards it (Unpublished master's thesis). Yarmouk University, Jordan. 
Al-Shammari, M. (2007). The effect of using the blended learning in teaching geography on the achievement of students of third middle grade in Hafer Albaten and their attitudes towards it (Unpublished doctoral dissertation). The University of Jordan.

Alshawa, H. \& Alhayek, S. (2009). Effects of using computer in learning among students anxiety. Damascus University Journal, 25(1), 35-67.

Al-Shyukh, G. (2008). Impediments to the use of blended learning from the point of view of faculty members (Unpublished master's thesis). College of Education, Arabian Gulf University, Bahrain.

Altun, A., Gulbahar, Y., \& Madran, O. (2008). Use of a content management system for blended learning: Perceptions of pre-service teachers. Turkish Online Journal of Distance Education-TOJDE, 9(4), 138-153

Anderson, A., Hattie, J., \& Hamilton, R. J. (2005). Locus of control, self-efficacy, and motivation in different schools: Is moderation the key to success? Educational Psychology, 25(5), 517-535.

Anu, F., \& Shannan, A. (2011). The differences in locus of control and self-concept between gifted and normal pupils in basic schools in Gezira State-Sudan. Arab Talent Development Journal, 3, 99-122.

Asiri, A, . (2007). Levels of anxiety facing students King Saud University in Riyadh (Unpublished doctoral dissertation). King Saud University, Saudi Arabia.

Badawi, M. (2009 March). Using blended learning for enhancing efl prospective teachers' pedagogical knowledge and performance. Conference Paper: Learning \& Language - The Spirit of the Age, Ain Shams University Guest House. Cairo, Egypt.

Bani Khalid, M. (2009).The relationship between locus of control and the level of academic achievement for the students of faculty of education. Journal of the Islamic University (Humanities series), 7(2), 491-512.

Barnard, L., Lan, W. Y., To, Y. M., Paton, V. O., \& Lai, S. L. (2009). Measuring self-regulation in online and blended learning environments. The Internet and Higher Education, 12, 1-6.

Batayneh, O., Aljrah, A., \& Ghawanima, M. (2007) Child Psychology. Amman: Dar Almseerah.

Birenbaum, M. (2007). Assessment and instruction preferences and their relationship with test anxiety and learning strategies. Higher Education, 53(6), 749-768.

Bishop, S. (2009). Trait anxiety and impoverished prefrontal control of attention. Nature Neuroscience, 12(1), 92-98.

Bowen, V. S. (1996). The relationship of locus of control and cognitive style to self instructional strategies, sequencing, and outcomes in a learner-controlled multimedia environment. Dissertation Abstracts International Section A: Humanities and Social Sciences, 56(10-A), 3922.

Cameron, I. (2005) Sustaining motivation in a blended learning environment (Unpublished master's thesis). Royal Roads University, Canada.

Cascio M., Botta V., \& Anzaldi V. (2013), The role of self efficacy and internal locus of control in online learning. Journal of e-Learning and Knowledge Society, 9(3) 95-106.

Chang, S. E. (2005). Computer anxiety and perception of task complexity in learning programming-related skills. Journal of Computers in Human Behavior, 21, 713-728. 
Daood, H. \& Mahmood, R. (2013, March).The effect of using blended teaching in the achievement of scientific fifth graders in chemistry and their attitudes towards this kind of teaching. Proceedings of the 2nd e-learning Regional Conference-State of Kuwait.

Duck, S. (1992). Human relationships. London : Stage.

Effandi, Z. \& Nordin, N.(2008). The effects of mathematics anxiety on matriculation students as related to motivation and achievement. Eurasia Journal of Mathematics, Science \& Technology Education, 4(1), 27-30.

Fong, S. F. \& Aldalalah, O. (2010). Modality and redundancy effects on music theory learning among pupils of different anxiety levels. International Journal of Behavioral, Cognitive, Educational and Psychological Sciences, 2(3), 167-175.

Fong, S. \& Aldalalah, O. (2010). Internals out-performing externals in music theory learning: A cognitive processing capacity perspective. Asian Social Science, 6(7) 70-80.

Gay, L. R. \& Airasian, P. W. (2003). Educational research: Competencies for analysis and application (7th ed). New York: Prentice Hall.

Gulbahar, Y. \& Madran, R. (2009). Communication and collaboration, satisfaction, equity, and autonomy in blended learning environments: A case from Turkey. International Review of Research in Open and Distance Learning, 10(2), 1-22.

Halpert, R. \& Hill, R. (2011). 28 measures of locus of control. Retrieved on 20 June 2014 from http://teachinternalcontrol.com/uploads/LOC_Measures_1_.pdf.

Hawwash, K. \& Elemat, M. (2006). The relationship between achievement motivation and test anxiety and its effect on the students' performance in English of the basic and secondary levels at Al-Mafraq city. Journal of Educational and Psychological Sciences. 7(3), 210222.

Haydar, A. (2009). Blended Learning in medicine collage. Journal of Engineering and Technology, 27(5), 190-199.

Hong, E. \& Karstensson, L. (2002). Antecedents of state test anxiety. Contemporary Educational Psychology, 27(2), 348-367.

Jay, R. M. (2007). Locus of control and academic achievement on high-stakes standardized tests (Unpublished master's thesis). Walden University.

Khader, K. (1993). Strategies and roadmap for effective higher education in Jordan. Definition approved by the General Conference of UNESCO at its 27th session. Amman: Ministry of Higher Education and Scientific Research in Jordan.

Kim, K., Bonk, C., \& Teng, Y. (2009). The present state and future trends of blended learning in workplace learning settings across five countries. Asia Pacific Education Review, 10(3), 299-308.

Kitchenham, A. (2005). Adult-learning principles, technology, elementary teachers and their students: The perfect blend? Education, Communication \& Information; 3(5) 285-302.

Konan, N. (2013). Educational supervisors' locus of control. Eurasian Journal of Educational Research, 51, 45-64.

Long, G., Vignare ,K., Rappold, R., \& Mallory, J. (2007). Access to communication for deaf, hard-of-hearing and ESL students in blended learning courses. International Review of Research in Open and Distance Learning, 8(3), 1-13. 
Mahar, D., Henderson, R., \& Deane, F. (1997). The effects of computer anxiety, state anxiety, and computer experience on users' performance of computer based tasks. Personality and Individual Differences, 22, 683-692.

Myllymäki, H. (2011). A blended learning solution and the impacts on attendance and learning outcomes. International Journal of Emerging Technologies in Learning, 6(2), 42-49

Nunn, G. \& Nunn, S. (1993). Locus of control and school performance: Some implications for teachers. Education, 113(4), 636-640.

Oluk, S., Oluko, O., \& Sakaci, T. (2009). Determination of state-trait anxiety levels of university students during the learning process of global environmental problems. China Education Review, 6(1), 49-53.

Orhan, F. (2008). Redesigning a course for blended learning environment. Turkish Online Journal of Distance Education, 9(1), 54-66.

Osguthorpe, R. T. \& Graham, C. R. (2003). Blended learning environments: Definitions and directions. Quarterly Review of Distance Education 4(3), 227-233.

Poborskii, A., Yurina, M., Lopatskaya, Z., \& Deryagina, E. (2009). The level of anxiety and state of autonomic regulation depending on the predicted examination grades in students living under unfavorable environmental conditions. Human Physiology, 35(4), 16-42.

Qtami, U. (2005). Educational psychology and thinking. Jordan: Dar Hanen.

Robison, R. (2004 ). Selected faculty experiences in designing and teaching blended learning courses at Brigham Young University (Unpublished doctoral dissertation). University of Nebraska.

Rotter, J. B. (1966). Generalized expectancies for internal versus external control of reinforcement. Psychological Monographs, 80(1) 1-28.

Rotter, J. B. (1990). Internal versus external control of reinforcement. A case in story of a varibal. American Psychology, 45(4), 489-493

Rotter, J. B. (1992). Cognates of personal control: Locus of control, self-efficacy, and explanatory style: Comment. Applied and Preventive Psychology, 1(2), 127-129.

Sa'ari, J., Luan, W., \& Roslan, S. (2005). Attitudes and perceived information technology competency among teachers. Malaysian Online Journal of Instructional Technology (MOJIT), 2(3), 70-77.

Sarason, I. G. (1972). Experimental approaches to test anxiety: Attention and the uses of information. In C. D. Spielberger (Ed.), Anxiety: Current trends in theory and research (Vol. 2, pp. 381-403). New York: Academic Press.

Sethy, S. (2008). Distance education in the age of globalization: An overwhelming desire towards blended learning. Turkish Online Journal of Distance Education, 9(3), 29-44.

Shabazz, K. M. (2007). The effects of environment and age on locus of control, self efficacy, and self esteem of military and non- military students' academic achievement (Unpublished doctoral dissertation). Tourou University International.

Shehab, S. (2007). Undergraduate learners' perceptions of blended learning and its relationship with some demographic and experiential variables at the Arab Open University-Bahrain Branch (Unpublished master's thesis). Arabian Gulf University, Bahrain. 
Stacey, E. \& Gerbic, P. (2008). Success factors for blended learning. Proceedings of the ASCILITE Conference (pp.964-968). Melbourne: ASCILITE.

Stocks, A., April, K., \& Lynton, N. (2012). Locus of control and subjective well-being - A crosscultural study. Problems and Perspectives in Management, 10(1), 17-25.

Thorne, K. (2003). Blended learning: How to integrate online \& traditional learning. London: Kogan.

Vaughan, N. (2007). Perspectives on blended learning in higher education. International Journal on E-Learning, 6(1), 81-94.

Warr, P. \& Downing, J. (2000). Learning strategies, learning anxiety, and knowledge acquisition. British Journal of Psychology, 91(3), 311-333.

Yair, L. (2007). Comparing dropouts and persistence in e-learning courses. Computers \& Education 48, 185-204

Zayadan, N. (2010). Factors affecting the use of information and communication technology (ICT) in Jordanian rural secondary schools (Unpublished doctoral dissertation). Malaysia: Universiti Sains Malaysia.

Correspondence: Osamah Ahmad Aldalalah, Ph.D., Instructional Technology Department, College of Education, Jadara University, Irbid, Jordan 